\title{
EDITORIAL
}

\section{Residência Médica em Medicina do Exercício e do Esporte e a consolidação da especialidade}

A Medicina do Exercício e do Esporte é uma das 52 especialidades reconhecidas conjuntamente pela Associação Médica Brasileira (AMB), pelo Conselho Federal de Medicina (CFM) e pela Comissão Nacional de Residência Médica (CNRM), por meio da Resolução CFM 1.666/2003. Há uma série de requisitos e critérios para definir uma determinada área do conhecimento como uma especialidade médica ou como uma área de atuação, subordinada a uma ou mais especialidades médicas.

A Medicina do Exercício e do Esporte possui assuntos e conteúdos específicos, alguns dos quais apresentam certo grau de interseção com outras especialidades, mas que no conjunto representam uma área de conhecimento bem delimitada.

A Medicina do Exercício e do Esporte é uma especialidade médica organizada nos diferentes níveis geográficos, sendo representada em nível nacional pela Sociedade Brasileira de Medicina do Exercício e do Esporte (SBME), entidade que fixou sede em São Paulo em 2003 e que tem marcante atuação no campo científico. Organiza anualmente o Congresso Brasileiro de Medicina do Exercício e do Esporte, que entre 07 e 09 de maio próximo terá a sua 21a edição no Centro de Convenções Rebouças, em São Paulo - SP. Tem regionais em atividade, também organizando periodicamente congressos, simpósios, jornadas e cursos de atualização. E internacionalmente, a SBME é filiada à Confederação Sul-Americana de Medicina do Esporte (COSUMED), à Confederação Panamericana de Medicina do Esporte (COPAMEDE) e à Federação Internacional de Medicina do Esporte (FIMS), com representantes do nosso país nas suas Diretorias.

A SBME tem na Revista Brasileira de Medicina do Esporte (RBME) o seu órgão oficial. A RBME está hoje indexada na maior parte das principais bases de dados internacionais, contando com um Conselho Editorial e um grupo de revisores ad hoc com profissionais respeitadíssimos nas suas áreas de atuação, constituindo-se em um periódico científico cuja qualidade é reconhecida inclusive fora das fronteiras do nosso país.

O concurso para obtenção do Título de Especialista em Medicina do Esporte (TEME) vem sendo realizada anualmente desde 1999 em parceria com a Associação Médica Brasileira. Antes de 1999, o TEME era concedido mediante análise curricular. Este processo vem sendo aprimorado a cada ano, com a organização de uma Prova Escrita cada vez mais abrangente e, desde o último ano, com a introdução de uma Prova Oral com quesitos práticos. A SBME está atualmente engajada no programa de acreditação da AMB, visando manter o especialista atualizado.

A formação na especialidade tem passado por aperfeiçoamentos recentes. Desde 1995 há na Universidade Federal Fluminense uma disciplina optativa específica sobre Medicina do Exercício e do Esporte, oferecida semestralmente para os alunos do curso de graduação em Medicina, exemplo que já foi seguido por diversas outras instituições de ensino superior no nosso país. É instintivo pensar que havendo a oportunidade de contato com o assunto durante o curso de graduação, um maior número de médicos poderá se interessar em seguir a especialidade. De fato, há vários cursos de Pós-Graduação lato sensu em Medicina do Esporte atualmente em atividade, formando especialistas em todo o país.

Mas acreditamos que o grande diferencial na formação de especialistas no país - que nos mostrará os seus resultados a médio e longo prazos - terá sido a criação da Residência Médica em Medicina do Exercício e do Esporte. A iniciativa partiu da SBME em 2003, particularmente do então Presidente, Dr. Ricardo Munir Nahas e do então Diretor Científico, Dr. Arnaldo José Hernandez. Após entendimentos com a AMB e a CNRM, foi elaborado o Programa de Residência Médica em Medicina do Exercício e do Esporte, que foi apresentado e discutido em reuniões formais e informais, em Brasília e em São Paulo, até a sua aprovação, em 13 de julho de 2005, por meio da Resolução CNRM 09/2005. Três instituições de ensino superior iniciaram o Programa de Residência Médica em 2007: a Universidade de Caxias do Sul (UCS), a Universidade de São Paulo (USP) e a Universidade Federal de São Paulo / Escola Paulista de Medicina (UNIFESP/EPM), cujas primeiras turmas terminarão a formação no final de 2009/início de 2010.

Enfim, muitos são os aspectos que caracterizam uma especialidade médica. A Medicina do Exercício e do Esporte tem passado por muitas mudanças, principalmente nos últimos 15 anos, que a vêm transformando de forma completa e definitiva. Este é um processo de consolidação e crescimento da especialidade, que simplesmente é o resultado do trabalho e da competência de profissionais que fazem do cumprimento da sua missão institucional a realização do que já foi um sonho, planejado e executado com a contribuição e o comprometimento de colegas de todo o Brasil.

Dr. José Kawazoe Lazzoli

Editor-Chefe, Revista Brasileira de Medicina do Esporte 